\title{
Enhanced dispersion stability and mobility of carboxyl- functionalized carbon nanotubes in aqueous solutions through strong hydrogen bonds
}

\author{
Yeon Kyoung Bahk $\cdot$ Xu He $\cdot$ Emmanouil Gitsis • \\ Yu-Ying Kuo $\cdot$ Nayoung Kim $\cdot$ Jing Wang
}

Received: 8 July 2015/ Accepted: 28 September 2015/Published online: 5 October 2015

(C) Springer Science+Business Media Dordrecht 2015

\begin{abstract}
Dispersion of carbon nanotubes has been heavily studied due to its importance for their technical applications, toxic effects, and environmental impacts. Common electrolytes, such as sodium chloride and potassium chloride, promote agglomeration of nanoparticles in aqueous solutions. On the contrary, we discovered that acetic electrolytes enhanced the dispersion of multi-walled carbon nanotubes (MWCNTs) with carboxyl functional group through the strong hydrogen bond, which was confirmed by UV-Vis spectrometry, dispersion observations and aerosolization-quantification method. When concentrations of acetate electrolytes such as ammonium acetate $\left(\mathrm{CH}_{3} \mathrm{CO}_{2} \mathrm{NH}_{4}\right)$ and sodium acetate $\left(\mathrm{CH}_{3} \mathrm{CO}_{2} \mathrm{Na}\right)$ were lower than $0.03 \mathrm{~mol}$ per liter,
\end{abstract}

Electronic supplementary material The online version of this article (doi:10.1007/s11051-015-3203-2) contains supplementary material, which is available to authorized users.

Y. K. Bahk · X. He - E. Gitsis - Y.-Y. Kuo .

J. Wang $(\bowtie)$

Institute of Environmental Engineering, ETH Zurich, 8093 Zurich, Switzerland

e-mail: jing.wang@ifu.baug.ethz.ch

Y. K. Bahk · X. He · Y.-Y. Kuo · J. Wang

Advanced Analytical Technologies, EMPA,

8600 Dübendorf, Switzerland

N. Kim

Building Energy Materials and Components, EMPA, 8600 Dübendorf, Switzerland
MWCNT suspensions showed better dispersion and had higher mobility in porous media. The effects by the acetic environment are also applicable to other nanoparticles with the carboxyl functional group, which was demonstrated with polystyrene latex particles as an example.

Keywords Carbon nanotubes - Nanoparticle · Dispersion - Acetic environment - Carboxylic functional group

\section{Introduction}

carbon nanotubes (CNTs), which possess extremely high aspect ratios, have been used in various applications because of their unique chemical, physical, and mechanical properties (Volder et al. 2013). Therefore, good understanding of CNT dispersion is significant, because of the needs for controlled CNT assembling or deposition with desired parameters such as the location, orientation, geometry, and density depending on the applications (Premkumar et al. 2012; Wu et al. 2013). Dispersion of CNTs is important not only for technical applications but also for the toxicity studies. Wick et al. (2007) showed that CNT-agglomerates are more cytotoxic than well-dispersed CNTs. For these reasons, the dispersion stability of CNTs in suspensions has been widely studied. Hydrophilic oxygencontaining functionalization by strong oxidizing agents is a popular surface modification to facilitate 
uniform dispersion of CNTs suspensions. For example, $\mathrm{HNO}_{3}, \mathrm{HNO}_{3} / \mathrm{H}_{2} \mathrm{SO}_{4}, \mathrm{O}_{3}, \mathrm{KMnO}_{4}$, or $\mathrm{H}_{2} \mathrm{O}_{2}$ is commonly used in order to functionalize CNTs (Balasubramanian and Burghard 2005; Smith et al. 2009; Zhang et al. 2003). Another method to enhance the dispersion of CNTs involves the use of surfactants (Kennedy et al. 2008). Several studies investigated enhanced stabilization with natural organic matter as a surfactant for dispersion of not only CNTs but also colloids in the aqueous phase (Hyung et al. 2007; Parks 1990; Schwarzenbach et al. 1993). Smith et al. (2009) investigated the relationship between the colloidal stability and $\mathrm{pH}$ of electrolyte solutions and showed that the stability of acid-treated MWCNTs increases with increasing $\mathrm{pH}$. For metal-based electrolytes, they also determined the critical coagulation concentration (CCC) of the electrolyte for acid-treated MWCNTs, and the results were consistent with the Derjaguin Landau Verwey Overbeek (DLVO) theory prediction (Askari and Abouie 2011).

In the DLVO theory, the stability of the suspension depends on the dispersion attractive force (van der Waals force) and electrostatic repulsion due to the presence of electric double layer of the charged objects (Bhattacharjee et al. 1998). The total free energy between two interacting objects (e.g., between two nanoparticles or a nanoparticle and plane surface) is the sum of potential energy due to the electrostatic repulsive force and van der Waals force (Masliyah and Bhattacharjee 2006). It should be noted that most of colloidal interactions take place in aqueous environment and unique characteristics of water bring nonDLVO interactions, such as hydrogen bonds, hydrophobic interactions, chemical (e.g., steric repulsion, bridging attraction, depletion force), and physical interactions (e.g., hydrodynamic attraction). The dispersion stability can be strongly affected by the non-DLVO interactions under specific conditions (Bunkin et al. 1997; Grasso et al. 2002; Israelachvili and Wennerström 1996; Jeffrey 1997; Ninham et al. 1997; Pauling 1960). When common electrolytes, such as sodium chloride $(\mathrm{NaCl})$ and potassium chloride $(\mathrm{KCl})$, are added into the solutions, the electrolytic cations and anions form hydrated ions due to the strong interaction among water molecules, cations, and anions (Bentz and Nir 1981; Bohidar et al. 2000; Fukasawa and Adachi 2010; Takayasu and Galembeck 1993). Based on the Lewis acid-base interaction theory, this leads to decreasing hydrophilicity of the
MWCNTs caused by the favorability of interaction between water molecules and electrolyte ions. Besides, the electrolytes also compress the electrical double layer, which favor the attraction of CNTs. It is already known that increasing electrolyte concentration in the suspension leads to decreasing solubility of oxidized CNTs (Smith et al. 2009; Peng et al. 2009).

On the contrary, we discovered that acetic solutions, for instance, $\mathrm{CH}_{3} \mathrm{CO}_{2} \mathrm{NH}_{4}$ and $\mathrm{CH}_{3} \mathrm{CO}_{2} \mathrm{Na}$, in a certain concentration range had opposite effects to the common electrolytes such as $\mathrm{NaCl}$ and $\mathrm{KCl}$ : they increased the dispersion stability of aqueous suspension of $\mathrm{COOH}-$ functionalized MWCNTs $(\mathrm{COOH}-$ MWCNTs). The reason lies in that the electrolytic acetic $\mathrm{CH}_{3} \mathrm{COO}^{-}$forms a stronger hydrogen bond with carboxyl than the bond between carboxyl and water molecule (Steiner 2002). We investigated the influence of acetate on $\mathrm{COOH}-\mathrm{MWCNTs}$ in the aqueous phase using $\mathrm{CH}_{3} \mathrm{CO}_{2} \mathrm{NH}_{4}$ and $\mathrm{CH}_{3} \mathrm{CO}_{2} \mathrm{Na}$ solutions, and observed enhanced dispersion stability. The enhanced dispersion stability also corresponded to higher mobility in porous media, which was demonstrated by the penetration of $\mathrm{COOH}-\mathrm{MWCNTs}$ through a model membrane filter. The mobility and dispersion statuses are closely interlinked, since the penetration of singly dispersed CNTs is easier than that of aggregated CNTs when sieving, interception, impaction, and gravity settling are the major capturing mechanisms. A series of experiments were performed to confirm the proposed effects of the electrolytic acetate. The stability of MWCNTs in $\mathrm{KCl}$ solutions was tested and compared with those of acetic samples. We additionally examined polystyrene latex (PSL) particles and carboxyl-functionalized PSL $(\mathrm{COOH}-$ PSL) particles in order to compare the acetate effects on the particles, with and without $\mathrm{COOH}$ functional group. The results are expected to be applicable not only for dispersion of COOH-MWCNTs but also for other nanoparticles with such functional group. Carboxyl functionalized graphene can be an example, which shares similar physical and chemical properties with CNTs as shown in a number of existing studies (Sun et al. 2008; Zhang et al. 2013).

\section{Materials and methods}

In order to investigate the dispersion stability of MWCNT suspensions, UV-Vis spectrophotometry, 
dispersity observations documented by a digital camera, and measurements of the particle penetration through the porous media were employed in this study. Pristine MWCNTs (Baytubes, BMS, Germany) possessing 15-20 nm diameters and carboxyl functionalized MWCNTs (which are referred to as C-MWCNTs in the following part) by the nitric acid refluxing method (Hu et al. 2003) were used to study the electrolyte effect. Suspensions of C-MWCNTs were prepared with deionized (DI) water, $\mathrm{CH}_{3} \mathrm{CO}_{2} \mathrm{NH}_{4}$, $\mathrm{CH}_{3} \mathrm{CO}_{2} \mathrm{Na}$, or $\mathrm{KCl}$ solutions. Different concentrations of ammonium acetate in the solutions were prepared for dispersity observation, and pristine MWCNT samples in DI water and $0.02 \mathrm{~mol}$ of $\mathrm{CH}_{3} \mathrm{CO}_{2} \mathrm{NH}_{4}$ per liter of solution were also prepared for comparison. The samples were kept for 14 days to observe aggregation of MWCNTs in the solution and measured by a UV-Vis spectrophotometer (Cary 50, Varian, USA) every day.

C-MWCNTs dispersed in aqueous $\mathrm{CH}_{3} \mathrm{CO}_{2} \mathrm{NH}_{4}$ and $\mathrm{KCl}$ solutions at different concentrations were used for the penetration measurements. The Nuclepore filters used in this study were $47 \mathrm{~mm}$ Whatman ${ }^{\circledR}$ Track-Etched Polycarbonate Membrane Filters with $3 \mu \mathrm{m}$ pore diameters, which were treated as a model membrane filter due to their uniform pore sizes and a flat front surface. The porosity and thickness of the filter were $0.14\left(2 \times 10^{6}\right.$ pores $\left./ \mathrm{cm}^{2}\right)$ and $0.9 \mu \mathrm{m}$, respectively.

Figure 1 shows the system set-up for the penetration measurement including UV-Vis spectrometry as well as the aerosolization-quantification method. The suspensions of C-MWCNTs were driven through the Nuclepore filter by a peristaltic pump, which provided a stable flow rate of $44 \mathrm{ml} / \mathrm{min}$. The average face velocity was calculated with the effective surface area of the Nuclepore filter $\left(8.0 \times 10^{-4} \mathrm{~m}^{2}\right)$, and the value was $9.1 \times 10^{-4} \mathrm{~m} / \mathrm{s}$. C-MWCNT concentrations upstream and downstream were measured by either the UV-Vis spectrophotometry or aerosolizationquantification method (Ling et al. 2010). Ling et al. (2010) investigated the method to evaluate the collection efficiency of liquid-borne nanoparticles by the filter. They found satisfactory correlations between the concentrations of liquid-borne and airborne particles when the liquid-borne particles were aerosolized and measured by the scanning mobility particle sizer (SMPS, TSI, USA). The SMPS delivers particle number versus size distributions, where the size is the equivalent mobility size representing the particle mobility in an electrical field.

The UV-Vis spectrophotometer was calibrated with different concentrations of C-MWCNTs in DI water. The curves of the scanning results for the wave length ranging from 350 to $900 \mathrm{~nm}$ are clearly distinguished for different samples as shown in Figure S1 in Supplementary information. The signal at $700 \mathrm{~nm}$ wavelength was chosen as the index for the C-MWCNT concentration in the suspension and Figure S2 in Supplementary information demonstrates the proportional relationship between the concentration and UV absorbance.

We also measured the amount of dispersed C-MWCNTs by the aerosolization-quantification method, in which the C-MWCNT suspensions were aerosolized by a Collison-type atomizer and measured by the SMPS. Several typical size distributions of airborne C-MWCNTs are shown in Fig. 2. The size of the C-MWCNT in such a measurement represents the diameter of an equivalent sphere which has the same electrical mobility as the C-MWCNT. The ratio of the upstream and downstream concentrations gave the penetration through the porous media, which was computed for different mobility sizes based on the SMPS results. On the other hand, the penetration of each sample was also calculated with the upstream and downstream concentrations of C-MWCNT suspensions determined by the UV-Vis spectrophotometry, which was an integral measurement and does not give size specific information. More detailed explanation to obtain penetration of C-MWCNTs through the porous media is given in Supplementary information.

The aerosolization-quantification method may not work for certain electrolytes and particle suspensions, because the electrolytes, surfactants, or impurities in the aerosolized droplets could condense and form particles in similar size range as the target particles, thus obscuring the intended particle size distribution. For instance, distributions of C-MWCNTs dispersed in $\mathrm{KCl}$ samples could not be distinguished from the background distributions obtained with the $\mathrm{KCl}$ solutions without any C-MWCNTs as shown in Figure S3 of Supplementary information. Therefore, for $\mathrm{KCl}$ based C-MWCNT suspensions, we obtained the total penetration of C-MWCNTs only by the UV-Vis spectrophotometer.

PSL particles of different sizes, such as 100, 200, and $300 \mathrm{~nm}$ (Magshpere Inc., USA), as well as 


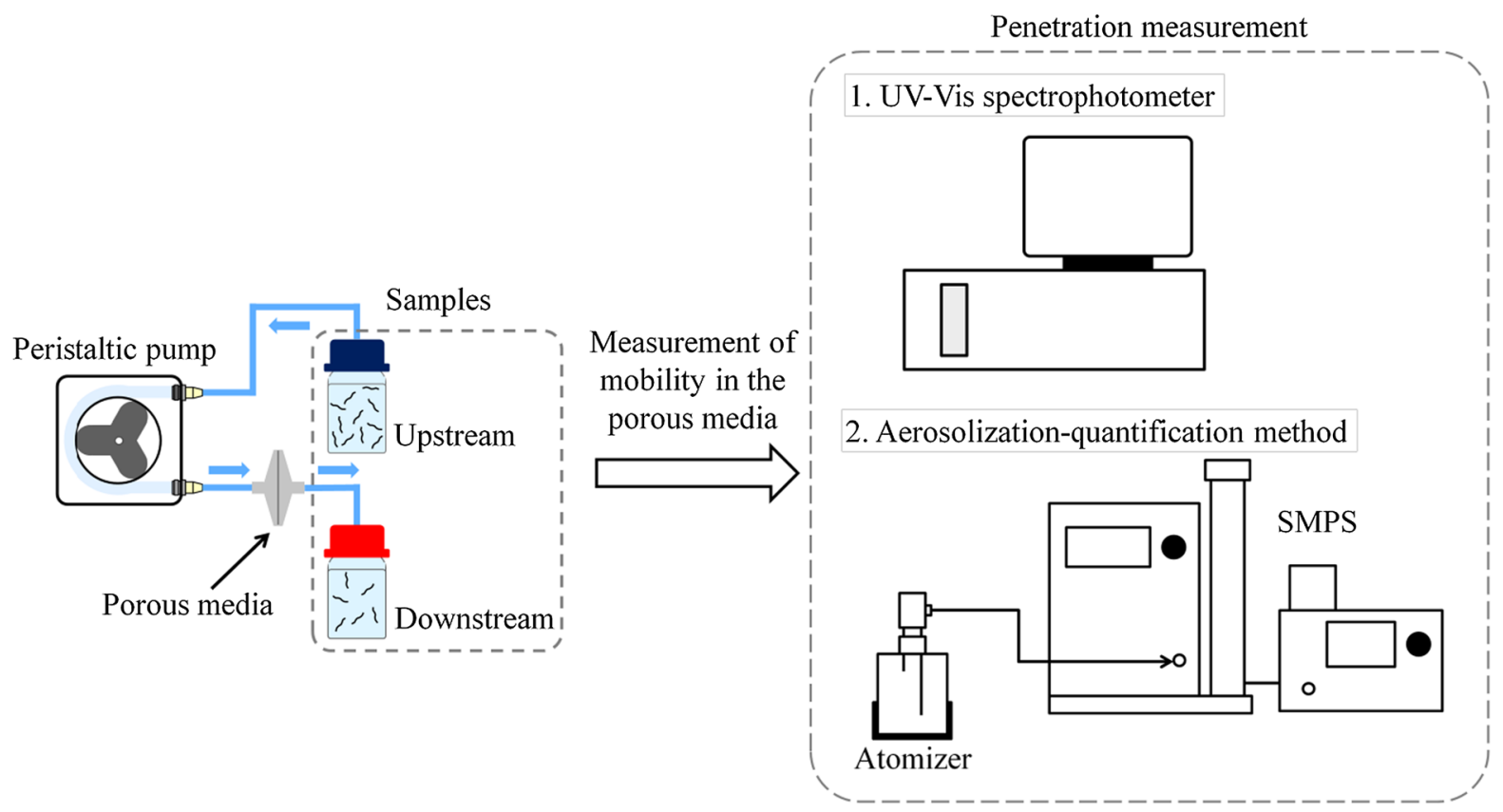

Fig. 1 Experimental system for mobility tests of C-MWCNTs in the aqueous solutions through the porous media

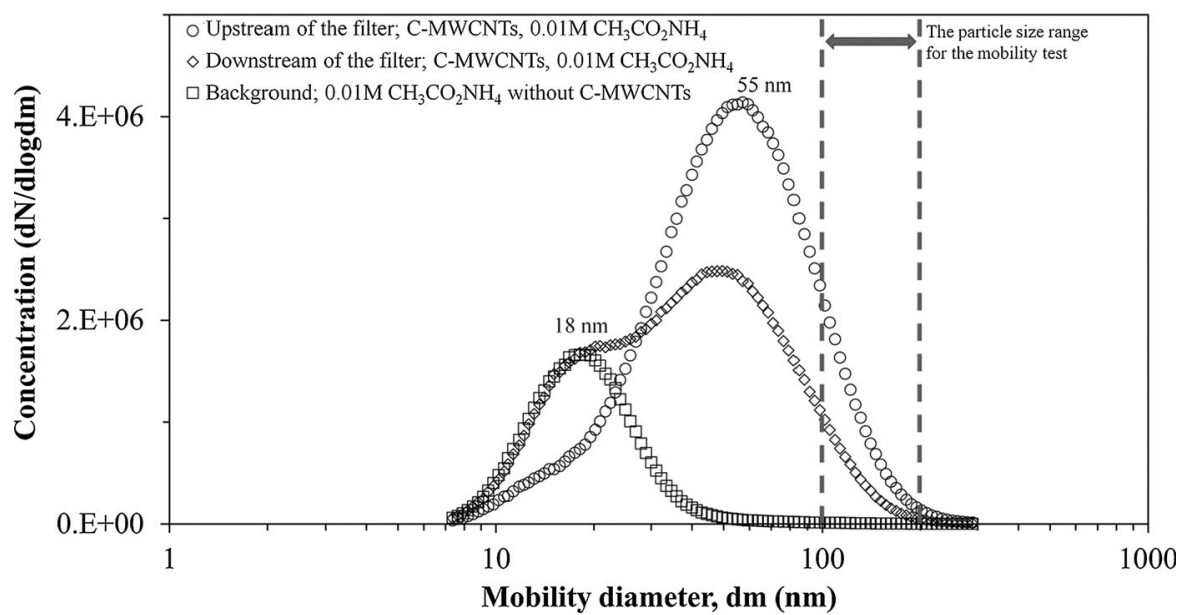

Fig. 2 Number concentration versus mobility size distributions of C-MWCNTs in the $\mathrm{CH}_{3} \mathrm{CO}_{2} \mathrm{NH}_{4}$ solution measured by the SMPS after aerosolization

COOH-PSL particles, such as 109, 217, and $300 \mathrm{~nm}$ (Agilent Technologies, USA), were used to test the acetate effect on dispersions of nanoparticles with and without carboxylic functional groups. Proprietary surfactants from the manufacturer existed in the purchased PSL and $\mathrm{COOH}-\mathrm{PSL}$ suspensions which facilitated stable dispersion in aqueous environment. Both UV-Vis spectrophotometry and aerosolization- quantification method were used to investigate the effect. Whatman ${ }^{\circledR}$-Track-Etched $47 \mathrm{~mm}$ Polycarbonate Membrane Filters with $1 \mu \mathrm{m}$ pore diameters were used for the penetration experiments.

The DLVO model was employed to understand adhesion between particles and particles on filter surface. The interaction between C-MWCNTs and the polycarbonate surface was simulated based on the 
model developed by Wu et al. (2013), and detailed explanation for the model and results are given in Supplementary information.

\section{Results}

Dispersion stability of MWCNT suspensions

Dispersion stability observations by a digital camera are shown in Fig. 3 in which the pictures were taken immediately, $24 \mathrm{~h}$, and one week after the solutions had been sonicated. $0.005 \mathrm{wt} \%$ of pristine MWCNTs and C-MWCNTs were dispersed in DI water, $\mathrm{CH}_{3-}$ $\mathrm{CO}_{2} \mathrm{NH}_{4}$, and $\mathrm{CH}_{3} \mathrm{CO}_{2} \mathrm{Na}$ solutions with different electrolyte concentrations, such as 0.01, 0.02, 0.03, 0.05 , and $0.1 \mathrm{M}$. The lower transparency of the suspension and homogeneous black solution can be considered as a qualitative indication of better dispersion (Shieh et al. 2007). As shown in Fig. 3, all pristine MWCNT samples aggregated considerably after the sonication process and quickly settled down to the bottom. On the other hand, C-MWCNT samples in $\mathrm{CH}_{3} \mathrm{CO}_{2} \mathrm{NH}_{4}$ and $\mathrm{CH}_{3} \mathrm{CO}_{2} \mathrm{Na}$ solutions showed stable dispersion when they were just prepared. $24 \mathrm{~h}$ after preparation, the C-MWCNT samples in both $0.1 \mathrm{M} \mathrm{CH}_{3} \mathrm{CO}_{2} \mathrm{NH}_{4}$ and $\mathrm{CH}_{3} \mathrm{CO}_{2} \mathrm{Na}$ solutions showed settlements on the bottom, leaving a transparent supernatant above. Other samples with concentrations from 0.01 to $0.05 \mathrm{M}$ of $\mathrm{CH}_{3} \mathrm{CO}_{2} \mathrm{NH}_{4}$ and $\mathrm{CH}_{3} \mathrm{CO}_{2} \mathrm{Na}$, and with DI water exhibited stable dispersion. One week after the sample preparation, the C-MWCNT samples with $0.05 \mathrm{M} \mathrm{CH}_{3} \mathrm{CO}_{2} \mathrm{NH}_{4}$ and $\mathrm{CH}_{3} \mathrm{CO}_{2} \mathrm{Na}$ showed aggregation and the others with lower acetic electrolyte concentrations or DI water displayed no visually discernible differences of dispersion stability. The observation results show that C-MWCNTs were stable for at least a week in the suspensions with $\mathrm{CH}_{3} \mathrm{CO}_{2} \mathrm{NH}_{4}$ or $\mathrm{CH}_{3} \mathrm{CO}_{2} \mathrm{Na}$ concentrations lower than $0.05 \mathrm{M}$, however, when the electrolyte concentrations were higher than $0.05 \mathrm{M}$ the stability decreased dramatically. The non-monotonic relation between the electrolyte concentration and the suspension stability was hypothetically caused by the competition between the effects of the hydrogen bond and the compression of the electrical double layer. Sample pictures for $\mathrm{CH}_{3} \mathrm{CO}_{2} \mathrm{Na}$ can be found in Figure $\mathrm{S} 4$ of Supplementary information.
C-MWCNTs suspensions with DI water and 0.01 , 0.02, 0.03, and $0.05 \mathrm{M}$ of $\mathrm{CH}_{3} \mathrm{CO}_{2} \mathrm{NH}_{4}$ or $\mathrm{CH}_{3} \mathrm{CO}_{2} \mathrm{Na}$ were stored for two weeks and measured several times using UV-Vis spectrophotometry to investigate the sample stability. Figures 4 and 5 show the measurement results of $\mathrm{CH}_{3} \mathrm{CO}_{2} \mathrm{NH}_{4}$ and $\mathrm{CH}_{3} \mathrm{CO}_{2} \mathrm{Na}$, respectively. All the freshly prepared C-MWCNT samples in $\mathrm{CH}_{3} \mathrm{CO}_{2} \mathrm{NH}_{4}$ and $\mathrm{CH}_{3} \mathrm{CO}_{2} \mathrm{Na}$ solutions showed higher absorbance, which indicated better dispersity, than the sample in DI water. The UV absorbance of the C-MWCNTs in the $0.05 \mathrm{M}$ samples started to drop significantly one day after sample preparation, accompanied by visual observation of aggregation of C-MWCNTs and separation of the sediment and supernatant. The absorbance for all other samples decreased slightly with time but stayed relatively stable for 2 weeks. The two samples 0.01 and $0.02 \mathrm{M}$ for each electrolyte showed higher absorbance than the DI water sample for the entire period. Both $0.03 \mathrm{M}$ samples with $\mathrm{CH}_{3} \mathrm{CO}_{2} \mathrm{NH}_{4}$ and $\mathrm{CH}_{3} \mathrm{CO}_{2} \mathrm{Na}$ showed steeper decreasing trend of absorbance than 0.01, $0.02 \mathrm{M}$ samples and DI water sample. Figure 6 shows the absorbance of C-MWCNTs in the suspensions with increasing electrolyte concentrations. The results are for samples 1 week after preparation and the two different acetic suspensions showed similar trends. The suspension stability first increased with the increasing electrolyte concentration until it reached the peak, which was about $0.01 \mathrm{M}$ for $\mathrm{CH}_{3} \mathrm{CO}_{2} \mathrm{NH}_{4}$ samples and $0.02 \mathrm{M}$ for $\mathrm{CH}_{3} \mathrm{CO}_{2} \mathrm{Na}$ samples, and then decreased when the concentrations increased further. The discrepancy between the two electrolytes was caused by different cations which affected the electrical double layer thickness. Since $\mathrm{NH}_{4}{ }^{+}$possesses bigger ionic radius $(1.43 \AA)$ than $\mathrm{Na}^{+}(0.95 \AA)$, it leads to a weaker ionic hydration (Marcus 1991; Tansel et al. 2006). Thus, the electrical double layer is compressed more due to weaker repulsion among $\mathrm{NH}_{4}{ }^{+}$counterions and the particle surfaces (Israelachvili and Pashley 1983; Goel 2006; Jorgensen and Weatherley 2003). Therefore, $\mathrm{NH}_{4}{ }^{+}$is more efficient to promote agglomeration of colloidal particles than $\mathrm{Na}^{+}$, and on the other hand, the acetic effect for dispersion of the samples with identical concentrations of the two electrolytes is the same. Thus, the concentration for the most stable condition with the $\mathrm{CH}_{3} \mathrm{CO}_{2} \mathrm{NH}_{4}$ samples was lower than that of $\mathrm{CH}_{3}$ $\mathrm{CO}_{2} \mathrm{Na}$ samples. 
Fig. 3 Dispersion statuses of pristine MWCNTs and C-MWCNTs in different solutions

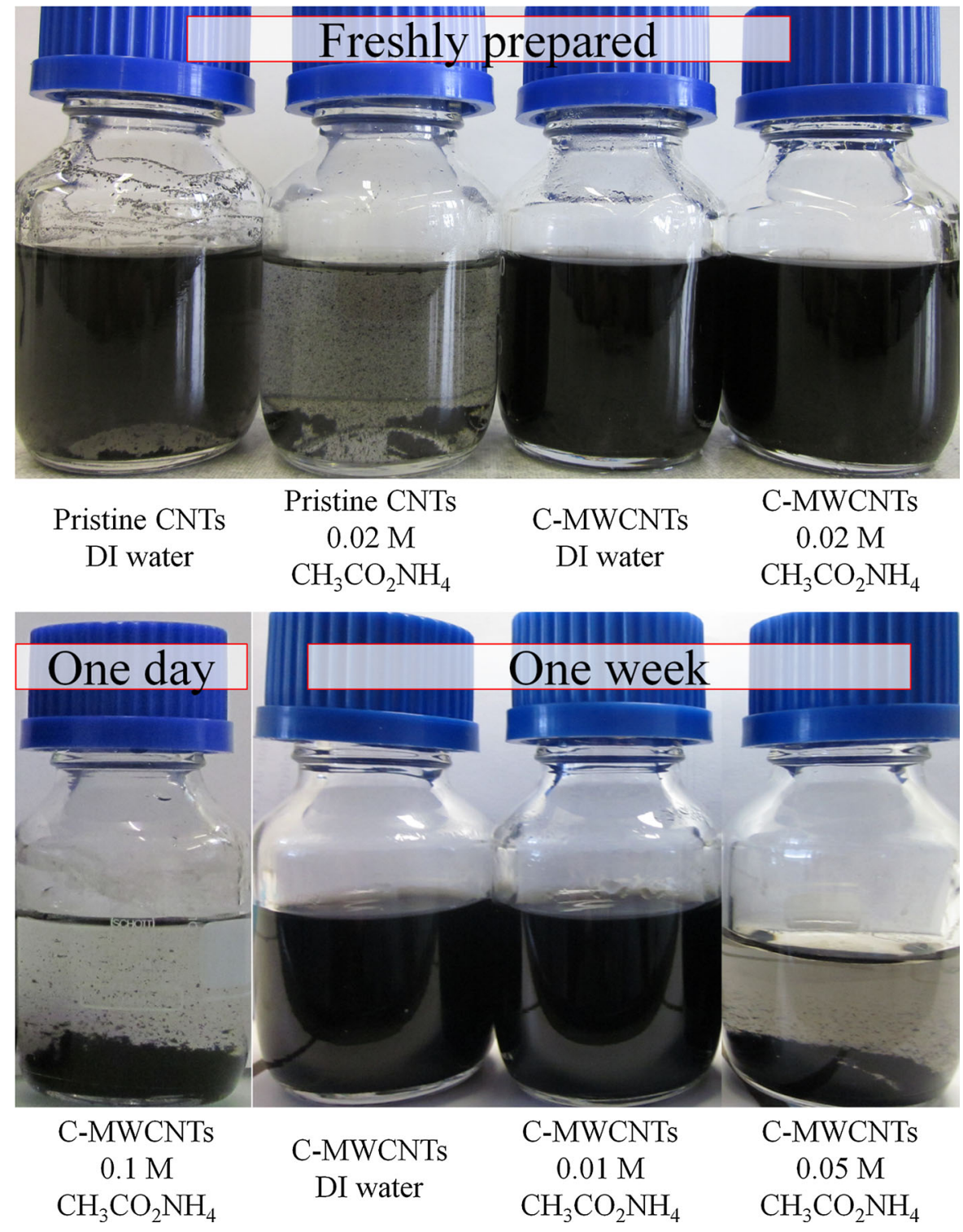

In order to check the consistency of the aerosol method with the UV-Vis spectrophotometry, samples prepared for penetration experiments were measured by both UV-Vis spectrophotometer and the SMPS. Figure 7 shows comparison between the two methods, which demonstrated similar trends depending on the ionic concentration. The ionic concentration of $\mathrm{CH}_{3-}$ $\mathrm{CO}_{2} \mathrm{NH}_{4}$ was varied as $0,0.007,0.01,0.014,0.021$, and $0.3 \mathrm{M}$, and the measured absorbance and particle number concentration at the mode of mobility size distribution were normalized by the values for DI water samples. The measured values increased when the ionic concentration increased until it reached
$0.014 \mathrm{M}$ and decreased with further increase of the ionic concentration. The inset figure in Fig. 7 presents SMPS results for the samples. The change of the peak size, which is closely related to the dispersion status (Bahk et al. 2013), was apparent with variation of the ionic concentration.

\section{Penetration tests using C-MWCNT suspensions}

The penetration experiments were performed using C-MWCNT samples in DI water and solutions with different concentrations of $\mathrm{CH}_{3} \mathrm{CO}_{2} \mathrm{NH}_{4}$ and $\mathrm{KCl}$. The samples with $\mathrm{CH}_{3} \mathrm{CO}_{2} \mathrm{NH}_{4}$ concentrations below 


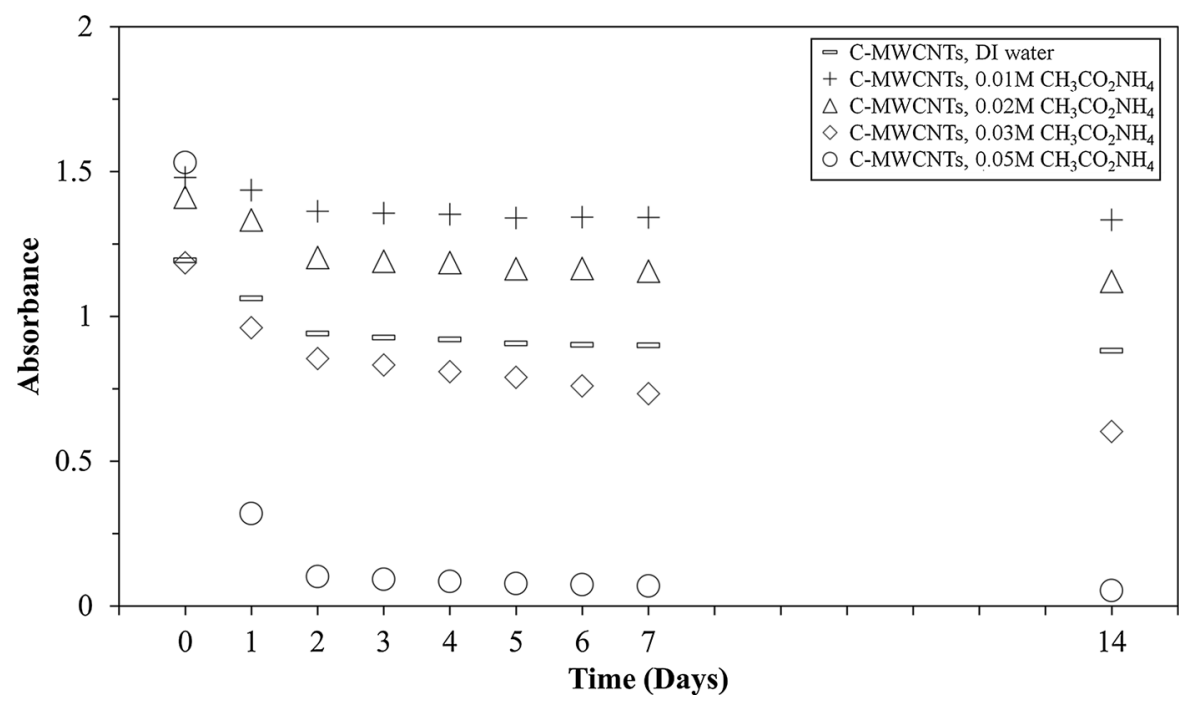

Fig. 4 Dispersion stability of C-MWCNT suspensions with different concentrations of $\mathrm{CH}_{3} \mathrm{CO}_{2} \mathrm{NH}_{4}$ in the solutions measured by UVVis spectrophotometer

Fig. 5 Dispersion stability of C-MWCNT suspensions with different concentrations of $\mathrm{CH}_{3} \mathrm{CO}_{2} \mathrm{Na}$ measured by $\mathrm{UV}-\mathrm{Vis}$ spectrophotometer

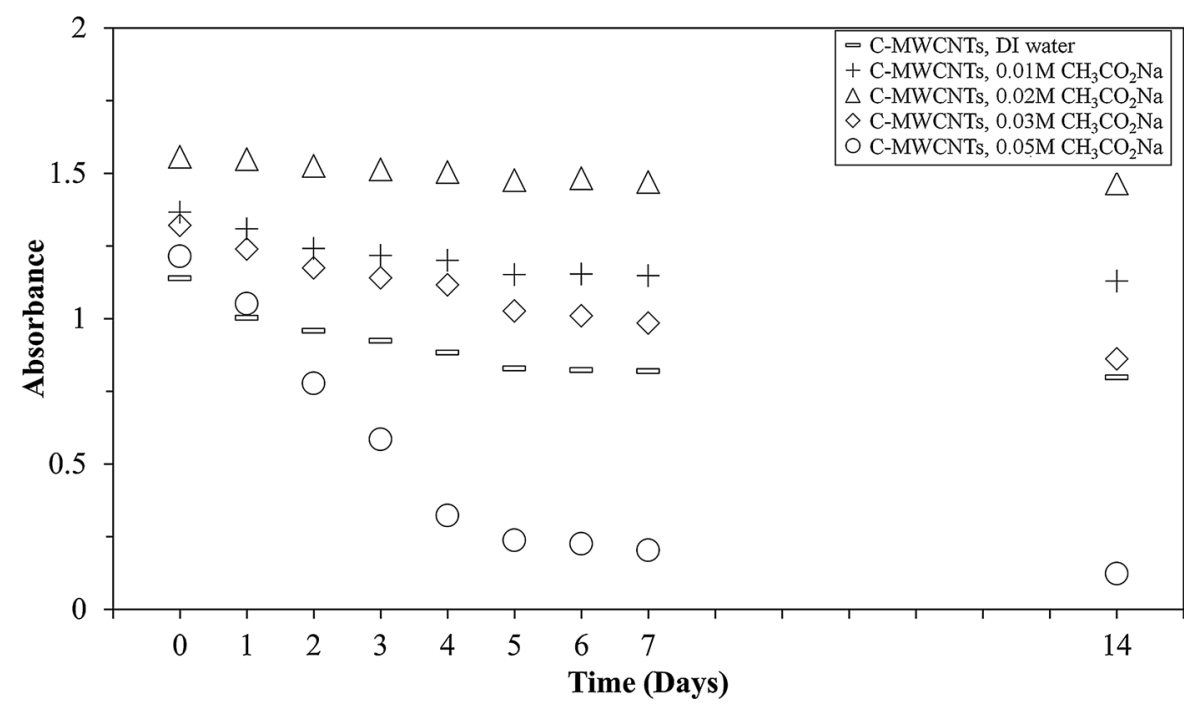

$0.02 \mathrm{M}$ showed higher penetrations than DI water and $\mathrm{KCl}$ samples (Fig. 8 and Table $\mathrm{S} 1$ ). This result was in agreement with our observation of better dispersity of C-MWCNTs in $\mathrm{CH}_{3} \mathrm{CO}_{2} \mathrm{NH}_{4}$ solutions shown in Fig. 7 because singly dispersed C-MWCNTs have higher mobility and are more likely to penetrate the porous media due to smaller geometrical sizes and possible alignment effect with the liquid flow. In contrast, C-MWCNTs in $\mathrm{KCl}$ solutions penetrated less than in DI water as shown in Table S1 which is consistent with the results in the literature (Jaisi and
Elimelech 2009) and can be explained by the classical DLVO theory. The electrical double layers of both the C-MWCNTs and porous media are compressed when the ionic strength increases, and hence, the electrostatic repulsive force and energy are reduced as shown in Figure S5. Furthermore according to the Lewis acid-base interaction theory, decreased hydrophilicity of C-MWCNTs caused by increasing interaction between electrolyte ions and water molecules, can also support the lower penetration of C-MWCNTs in $\mathrm{KCl}$ solutions than in DI water. The inset of Fig. 8a 
Fig. 6 UV absorbance of C-MWCNT dispersed suspensions with different concentrations of electrolytes in the solutions

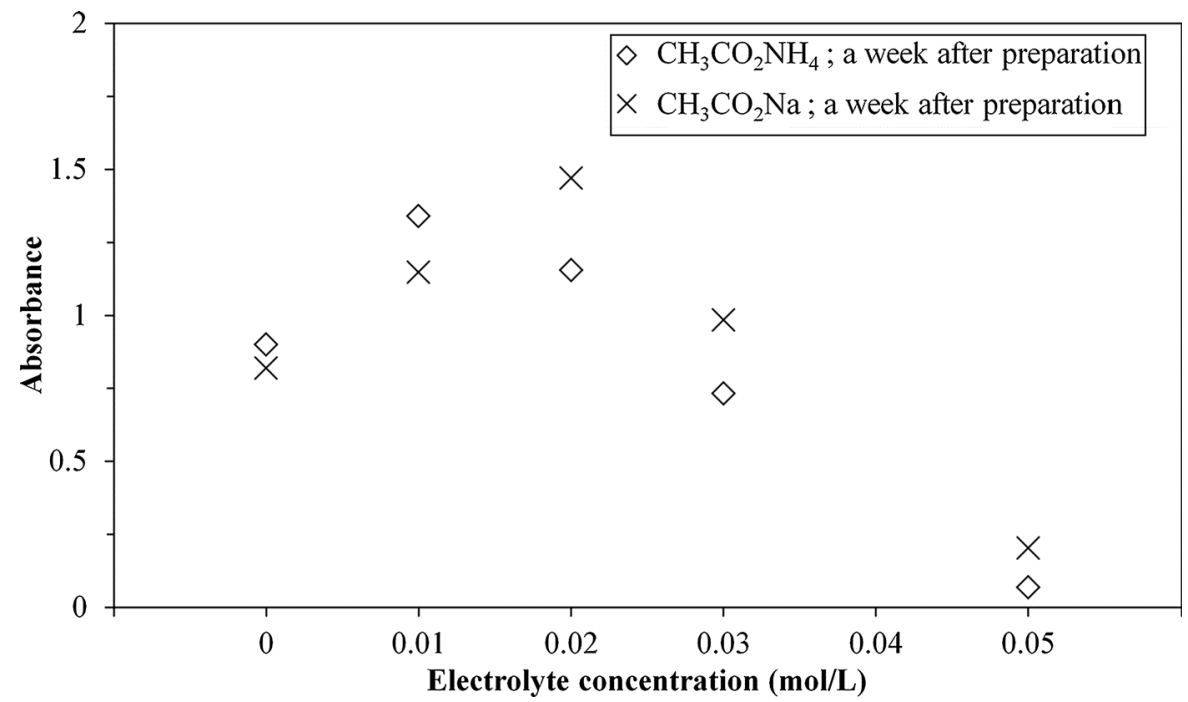

Fig. 7 Normalized absorbance measured by UV-Vis spectrophotometer (Right) and number concentrations measured by SMPS at the mode of mobility size distributions (Left) for C-MWCNT suspensions with different concentrations of $\mathrm{CH}_{3} \mathrm{CO}_{2} \mathrm{NH}_{4}$

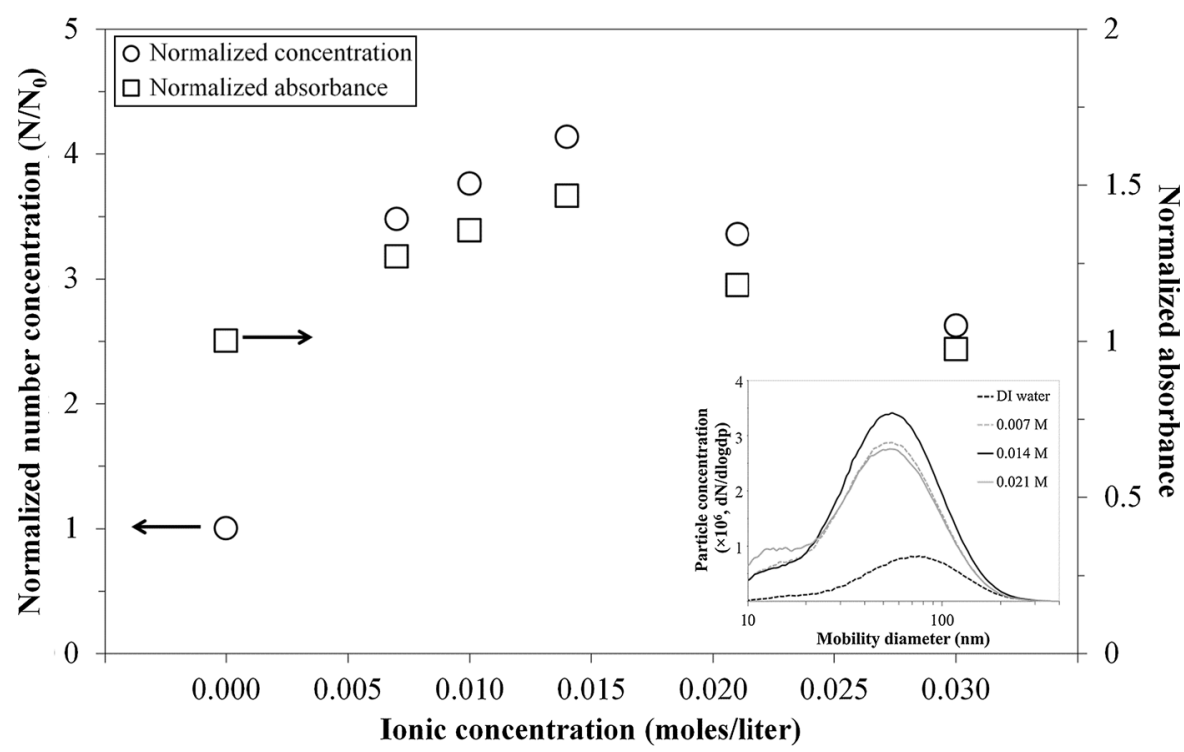

curve crossed that for the DI water sample. The two penetration curves were in a similar range, which agrees with the fact that the overall efficiencies for the two samples were similar as shown in Fig. 8a.

Dispersion stability of PSL suspensions

The dispersion stability of PSL particles in DI water and $\mathrm{CH}_{3} \mathrm{CO}_{2} \mathrm{NH}_{4}$ solutions were also measured by the $\mathrm{UV}-\mathrm{Vis}$ spectrophotometer, and the results are presented in Fig. 9. COOH-PSL particle suspensions with 0.01 and $0.02 \mathrm{M} \mathrm{CH}_{3} \mathrm{CO}_{2} \mathrm{NH}_{4}$ as well as PSL 
Fig. 8 Penetration of C-MWCNTs in the $\mathrm{CH}_{3} \mathrm{CO}_{2} \mathrm{NH}_{4}$ suspensions through the porous media measured by (a) UV-Vis spectrophotometer (b) SMPS for 100-200 nm mobility size range. The inset of (a) shows photos of the samples with different ionic concentrations after penetration, and the numbers above the data points indicate the samples
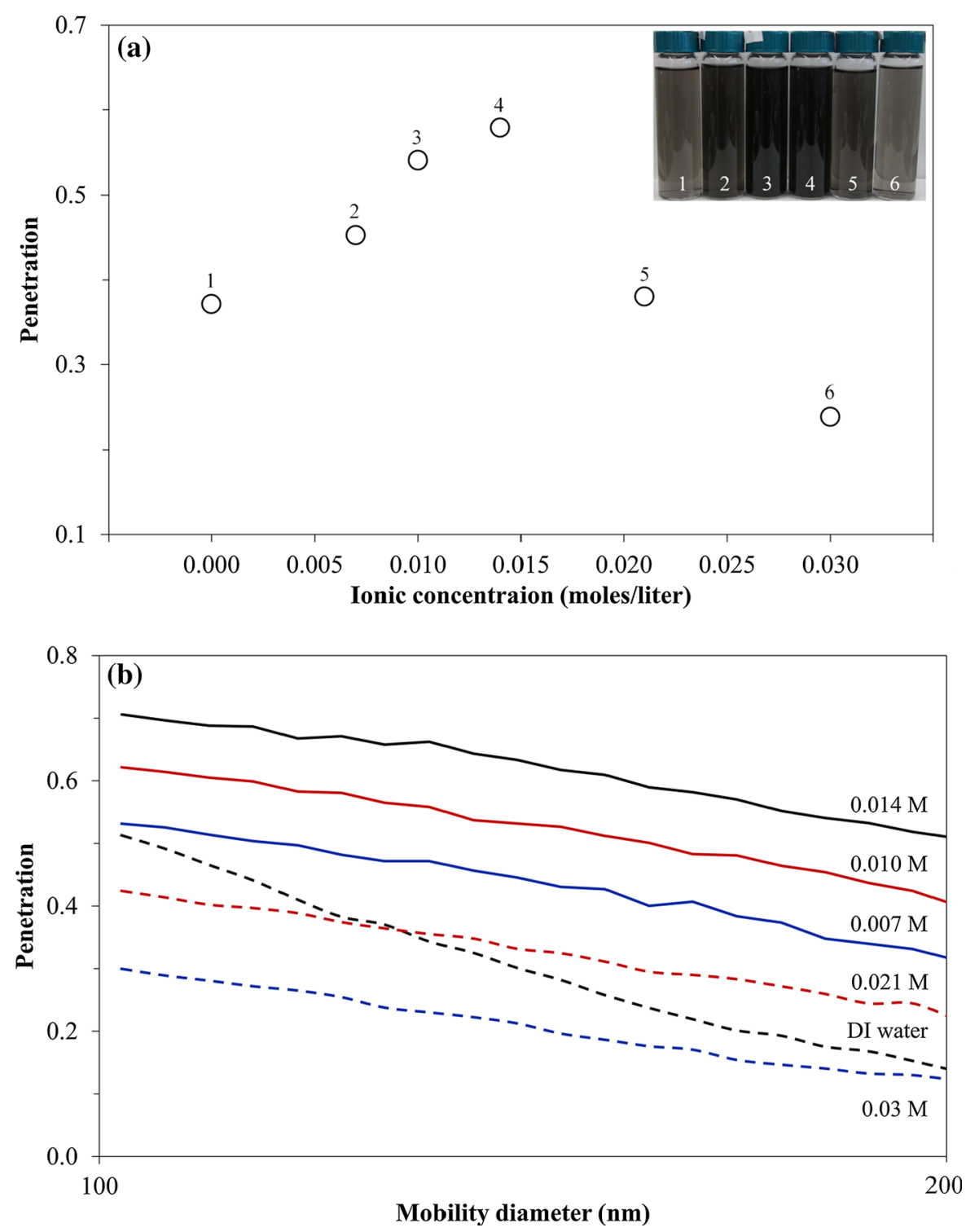

samples with and without carboxyl functional groups in DI water showed stable conditions for more than two weeks. The absorbance of the COOH-PSL sample with $0.05 \mathrm{M} \mathrm{CH}_{3} \mathrm{CO}_{2} \mathrm{NH}_{4}$ continuously decreased for the entire period; the UV absorbance for the PSL samples without the carboxyl functional group with 0.01 and $0.02 \mathrm{M} \mathrm{CH}_{3} \mathrm{CO}_{2} \mathrm{NH}_{4}$ decreased at similar rates. The PSL samples with $0.1 \mathrm{M} \mathrm{CH}_{3} \mathrm{CO}_{2} \mathrm{NH}_{4}$ settled down quickly after preparation. The above results showed that the $\mathrm{COOH}-\mathrm{PSL}$ samples in the acetic solutions with low ionic concentrations $(0.01$ and $0.02 \mathrm{M}$ ) were stable; however, the dispersion of PSL samples in DI water was already stable, and no enhancement by the carboxyl-acetate hydrogen bond was observed. In the PSL samples with high ionic concentrations $(0.05$ and $0.1 \mathrm{M})$, the normal electrolyte effect became apparent and particle agglomeration was promoted.

Penetration tests using PSL suspensions

The aerosolization-quantification method was used for the penetration experiments using PSL and $\mathrm{COOH}-$ PSL particles in different solutions, and the results are shown in Fig. 10. The penetrations for PSL particles in DI water were close to $100 \%$, which were attributed 
Fig. 9 Changes of dispersion stabilities of PSL and $\mathrm{COOH}-\mathrm{PSL}$ particle suspensions with different concentrations of electrolytes in the solutions

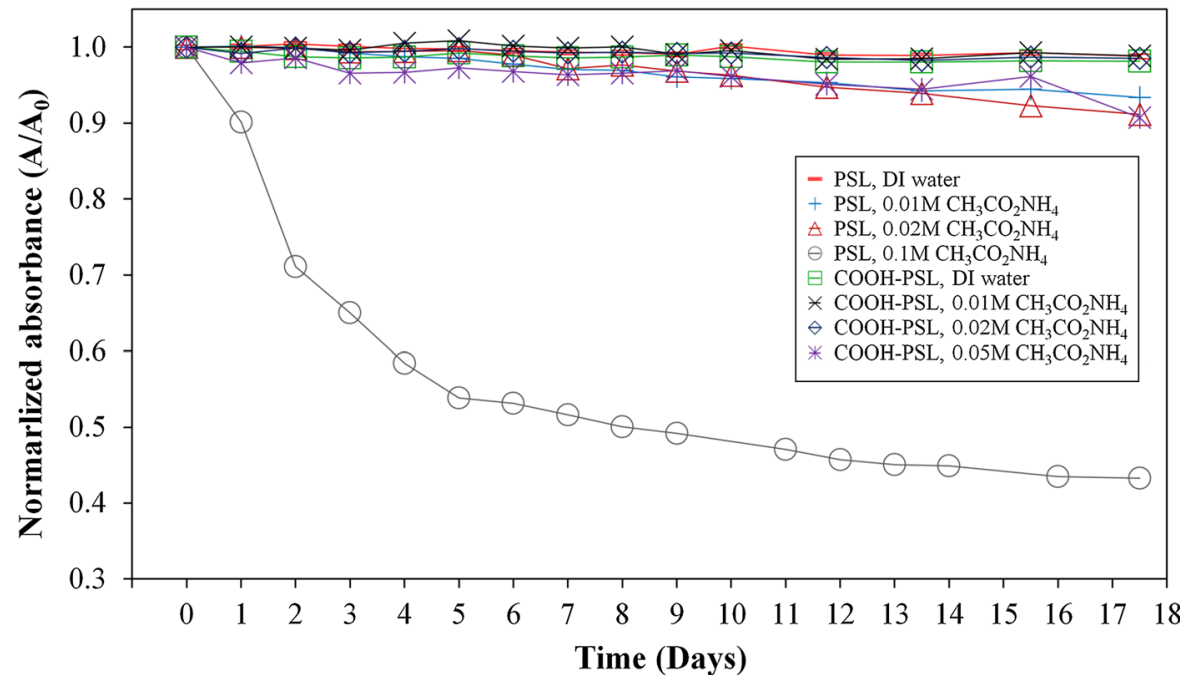

to the good dispersion and low attachment efficiency of PSL particles on the filter surfaces. The calculated energy barrier of the system by DLVO theory, which can be found in Figure S6 of Supplementary information, was so high that PSL particles could hardly overcome it to achieve permanent attachment to the contact surfaces. The penetrations of $\mathrm{COOH}-\mathrm{PSL}$ particles in $\mathrm{CH}_{3} \mathrm{CO}_{2} \mathrm{NH}_{4}$ solutions with different concentrations were essentially as high as the PSL sample in DI water. In contrast, $\mathrm{CH}_{3} \mathrm{CO}_{2} \mathrm{NH}_{4}$ acted as a normal electrolyte and adding $\mathrm{CH}_{3} \mathrm{CO}_{2} \mathrm{NH}_{4}$ resulted in decreasing penetrations for PSL particles without the functional group. Our penetration tests did not show improved mobility due to the carboxyl-acetate hydrogen bond compared to the PSL sample in DI water; however, the results confirmed that the acetic electrolyte acted differently than normal electrolytes. The beneficial effects of the carboxyl-acetate hydrogen bond on dispersity and mobility seemed to balance out the normal electrolyte effects for $\mathrm{COOH}-\mathrm{PSL}$ particles.

\section{Discussion}

The enhancement of dispersion stability achieved in the study can be explained by a strong hydrogen bond between the electrolytic $\mathrm{CH}_{3} \mathrm{COO}^{-}$and carboxyl. To
Fig. 10 Penetrations of PSL and COOH-PSL particles in the suspensions with different electrolyte concentrations through the Nuclepore filter

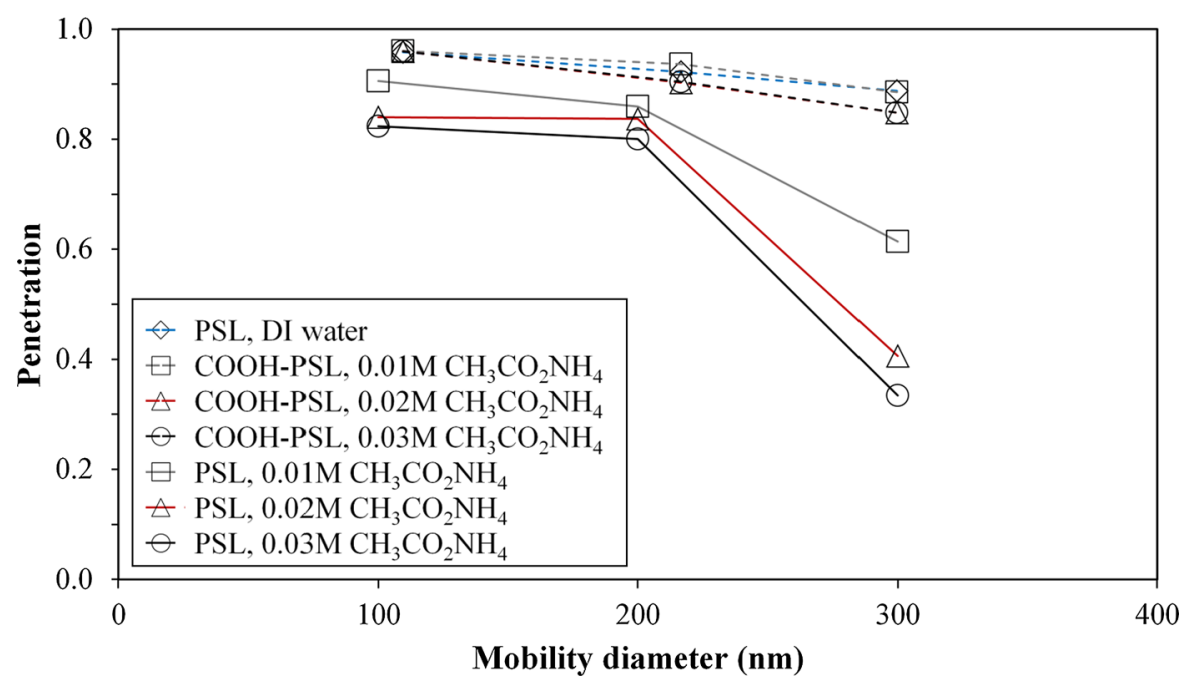




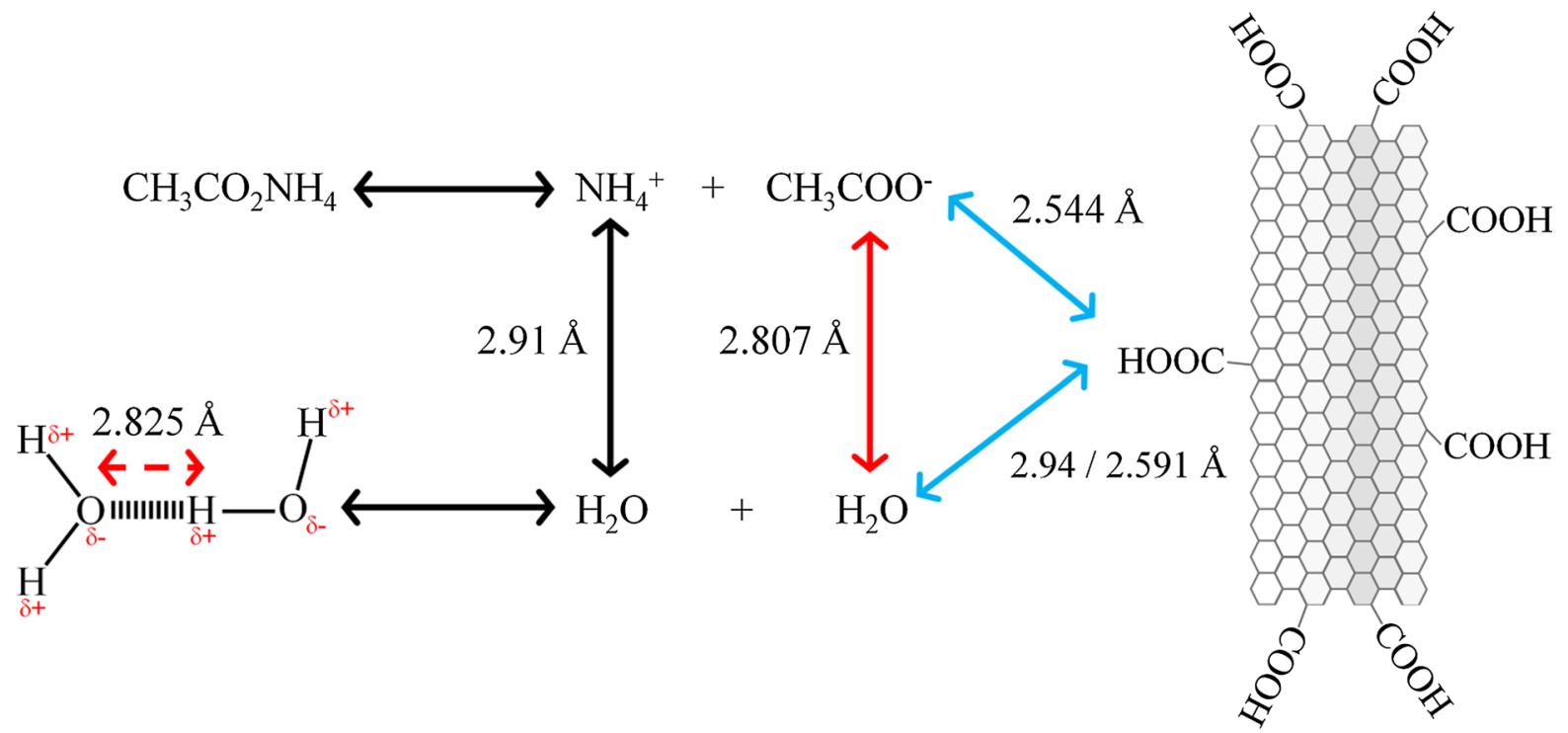

Fig. 11 The mean distances of $\mathrm{O}$ atoms in different hydrogen bonds, such as carboxyl and $\mathrm{CH}_{3} \mathrm{COO}^{-}$, carboxyl and water molecule and, $\mathrm{CH}_{3} \mathrm{COO}^{-}$and water molecule

enhance dispersion of nanoparticles with the carboxyl functional group in aqueous solutions, the hydrogen bond between $\mathrm{CH}_{3} \mathrm{COO}^{-}$and carboxyl should be stronger and more competitive than other influencing bonds, such as hydrogen bonds between carboxyl and water molecules, acetate and water molecules, and suppression of the double layer by electrolyte ions in the solutions additionally. Figure 11 describes the strength of intermolecular $\mathrm{O}-\mathrm{H}$... O hydrogen bonds between different molecules, and it can be reflected by the mean distance of O...O. The values are 0.2544 , $0.294 \mathrm{~nm}$ (or $0.2591 \mathrm{~nm}$ due to different hydrogen donor and acceptor), and $0.2807 \mathrm{~nm}$ for bonds between carboxyl and $\mathrm{CH}_{3} \mathrm{COO}^{-}$, carboxyl and water molecule, $\mathrm{CH}_{3} \mathrm{COO}^{-}$and water molecule, respectively (Steiner 2002). So the hydrogen bond between carboxyl and $\mathrm{CH}_{3} \mathrm{COO}^{-}$is strongest in the suspension system. Quantitative comparison between the effect of the carboxyl- $\mathrm{CH}_{3} \mathrm{COO}^{-}$hydrogen bond and the effect of electrolyte ions on the electrical double layer is not yet theoretically available; however, according to our results, the hydrogen bond was more influential on the dispersity than the effect of electrolyte ions on the shrinkage of electrical double layer when concentrations of acetic ions were below certain concentrations (approximately $0.03 \mathrm{M}$ for both $\mathrm{CH}_{3} \mathrm{CO}_{2} \mathrm{NH}_{4}$ and $\mathrm{CH}_{3} \mathrm{CO}_{2} \mathrm{Na}$ in this study) and vice versa when the acetic concentration was higher than the threshold.
Previous studies (Shieh et al. 2012; Heister et al. 2010) show that the ionization of the carboxyl groups on CNT surface is varied by concentration of electrolyte, due to the correlated change in the $\mathrm{pH}$ value. The carboxyl group tends to be dissociated and negatively charged in a high $\mathrm{pH}$ solution so that CNT dispersity is improved with increase of the $\mathrm{pH}$ value. However, this effect cannot explain the results in the present study, since both of the acetic electrolytes employed in our experiments are commonly used to prepare buffer solutions. The $\mathrm{pH}$ values of ammonium acetate solutions stayed in a narrow range (6.98-7.11) for the entire concentration range (0.01-0.2 M); meanwhile for sodium acetate, that value increased mildly from 6.99 to 7.95 with the concentration increasing. In the measured $\mathrm{pH}$ range, the zeta potential of the CNTs, which corresponds to the electrostatic repulsion between particles, only has a minor change (Heister et al. 2010) and cannot account for the observed change of the CNT dispersity in our experiments.

\section{Conclusions}

We observed that acetic electrolytes had opposite effects compared with other electrolytes, such as $\mathrm{NaCl}$ and $\mathrm{KCl}$, to enhance the dispersion stability and 
mobility in porous media of suspensions of carboxyl functionalized MWCNTs. The conclusion was based on results of the UV-Vis spectrometry, observation by the digital camera, and penetration tests through porous media. Sodium and ammonium acetates both demonstrated the above effects when the ionic concentrations were below certain thresholds. These observations can be explained by the strong hydrogen bond between the electrolytic $\mathrm{CH}_{3} \mathrm{COO}^{-}$and carboxyl. The hydrogen bond was more influential and competitive than other interactive effects within the concentration threshold of acetic ions. Enhanced dispersion was not observed for PSL particles due to already effective dispersion of PSL in DI water; however, the effect of the carboxyl-acetate hydrogen bond was also observed for the COOH-PSL suspensions. The results provide new possibilities for control of dispersion stability and mobility of nanoparticles with the carboxyl functional group.

Acknowledgments This study was partially supported by the Swiss National Science Foundation (NFP 64), "Evaluation platform for safety and environment risks of carbon nanotube reinforce nanocomposites," 406440_131286.

\section{References}

Askari M, Abouie J (2011) A closed form for the electrostatic interaction between two rod-like charged objects. J Phys 23(15):155103-155108

Bahk YK, Buha J, Wang J (2013) Determination of geometrical length of airborne carbon nanotubes by electron microscopy, model calculation, and filtration method. Aerosol Sci Technol 47(7):776-784

Balasubramanian K, Burghar M (2005) Chemically functionalized carbon nanotubes. Small 1(2):180-192

Bentz J, Nir S (1981) Aggregation of colloidal particles modeled as a dynamical process. Proc Natl Acad Sci USA 78(3):1634-1647

Bhattacharjee S, Elimelech M, Borkovec M (1998) DLVO interaction between colloidal particles: beyond Derjaguin's approximation. Croat Chem Acta 71:883-903

Bohidar HB, Bhakat P, Sharma J, Saxena A (2000) Anomalous colloidal stability of protein coated polystyrene latex beads studies by small angle light scattering. Int J Biol Macromol 27:111-116

Bunkin NF, Kiseleva OA, Lobeyev AV, Movchan TG, Ninham BW, Vinogradova OI (1997) Effect of salts and dissolved gas on optical cavitation near hydrophobic and hydrophilic surfaces. Langmuir 13:3024-3028

Fukasawa T, Adachi Y (2010) Direct observation on the Brownian coagulation of PSL particles through optical microscope in the regime near critical coagulation concentration (CCC). J Colloid Interf Sci 344(2):343-347
Goel A (2006) Colloidal chemistry. Discovery Publishing House, New Delhi

Grasso D, Subramaniam K, Butkus M, Strevett K, Bergendahl J (2002) A review of non-DLVO interactions in environmental colloidal systems. Rev Environ Sci BioTechnol 1:17-38

Heister E, Lamprecht C, Neves V, Tilmaciu C, Datas L, Flahaut E, Soula B, Hinterdorfer P, Coley HM, Silva SRP, McFadden J (2010) Higher dispersion efficacy of functionalized carbon nanotubes in chemical and biological environments. ACS Nano 4:2615-2626

$\mathrm{Hu} \mathrm{H}$, Zhao B, Itkis ME, Haddon RC (2003) nitric acid purification of single-walled carbon nanotubes. J Phys Chem B 107:13838-13842

Hyung H, Fortner JD, Hughes JB, Kim JH (2007) Natural organic matter stabilizes carbon nanotubes in the aqueous phase. Environ Sci Technol 41:179-184

Israelachvili JN, Pashley RM (1983) Molecular layering of water at surfaces and origin of repulsive hydration forces. Nature 306:249-250

Israelachvili JN, Wennerström H (1996) Role of hydration and water structure in biological and colloidal interactions. Nature 379:219-224

Jaisi DP, Elimelech M (2009) Single-walled carbon nanotubes exhibit limited transport in soil columns. Environ Sci Technol 43:9161-9166

Jeffrey GA (1997) An introduction to hydrogen bonding. Oxford University Press, New York

Jorgensen TC, Weatherley LR (2003) Ammonia removal from wastewater by ion exchange in the presence of organic contaminants. Water Res 37:1723-1728

Kennedy AJ, Hull MS, Steevens JA, Dontsova KM, Chappell MA, Gunter JC, Weiss CA Jr (2008) Factors influencing the partitioning and toxicity of nanotubes in the aquatic environment. Environ Toxicol Chem 27(9):1932-1941

Ling TY, Wang J, Pui DYH (2010) Measurement of retention efficiency of filters against nanoparticles in liquids using an aerosolization technique. Environ Sci Technol 44:774-779

Marcus Y (1991) Thermodynamics of solvation of ions: Part 5. Gibbs free energy of hydration at 298.15 K. J Chem Soc Faraday Trans 87(18):2995-2999

Masliyah JH, Bhattacharjee S (2006) Electrokinetic and colloid transport phenomena. John Wiley \& Sons, Hoboken

Ninham BW, Kurihara K, Vinogradova OI (1997) Hydrophobicity, specific ion adsorption and reactivity. Colloids Surf A $123-124: 7-12$

Parks GA (1990) Surface energy and adsorption at mineralwater interfaces: an introduction. Rev Mineral Geochem 23:133-175

Pauling L (1960) The nature of the chemical bond. Cornell University Press, Ithaca

Peng X, Jia J, Gong X, Luan Z, Fan B (2009) Aqueous stability of oxidized carbon nanotubes and the precipitation by salts. J Hazard Mater 165:1239-1242

Premkumar T, Mezzenga R, Geckeler KE (2012) Carbon nanotubes in the liquid phase: addressing the issue of dispersion. Small 8(9):1299-1313

Schwarzenbach RP, Gschwend PM, Imboden DM (1993) Environmental organic chemistry. John Wiley \& Sons, New York

Shieh Y, Liu G, Wu H, Lee C (2007) Effect of polarity and pH on the solubility of acid-treated carbon nanotubes in different media. Carbon 45:1880-1890 
Shieh YT, Chen JY, Twu YK, Chen WJ (2012) The effect of pH and ionic strength on the dispersion of carbon nanotubes in poly (acrylic acid) solutions. Polym Int 61:554-559

Smith B, Wepasnich K, Schrote KE, Bertele AR, Ball WP, O'Melia C, Fairbrother DH (2009) Colloidal properties of aqueous suspensions of acid-treated, multi-walled carbon nanotubes. Environ Sci Technol 43:819-825

Steiner T (2002) The hydrogen bond in the solid state. Angew Chem Int Ed Engl 41(1):49-76

Sun X, Liu Z, Welsher K, Robinson JT, Goodwin A, Zaric S, Dai $\mathrm{H}$ (2008) Nano-graphene oxide for cellular imaging and drug delivery. Nano Res 1(3):203-212

Takayasu MM, Galembeck F (1993) Polystyrene latex coagulation: a study using centrifugation in density gradients. J Colloid Interf Sci 155:16-22

Tansel B, Sager J, Rector T, Garland J, Strayer R, Lanfang L, Roberts M, Hummerick M, Bauer J (2006) Significance of hydrated radius and hydration shells on ionic permeability during nanofiltration in dead end and cross flow modes. Sep Purif Technol 51:40-47
Volder MFL, Tawfick SH, Baughman RH, Hart AJ (2013) Carbon nanotubes: present and future commercial applications. Science 339:535-539

Wick P, Manser P, Limbach LK, Dettlaff-Weglikowska U, Krumeich F, Roth S, Stark WJ, Bruinink A (2007) The degree and kind of agglomeration affect carbon nanotube cytotoxicity. Toxicol Lett 168:121-131

Wu L, Gao B, Tian Y, Muñoz-Carpena R, Zigler KJ (2013) DLVO interactions of carbon nanotubes with isotropic planar surfaces. Lagnmuir 29:3976-3988

Zhang J, Zou H, Qing Q, Yang Y, Li Y, Liu Z, Guo X, Du Z (2003) Effect of chemical oxidation on the structure of single-walled carbon nanotubes. J Phys Chem B 107:3712-3718

Zhang K, Heo N, Shi X, Park JH (2013) Chemically modified graphene oxide-wrapped quasi-micro Ag decorated silver trimolybdate nanowires for photocatalytic applications. J Phys Chem C 117(45):24023-24032 